\title{
The Importance of Structures and Concrete Reservoirs in Passive Defense and Ways to strengthen them
}

\author{
Amir Hossein Ghiamati YAZDI ${ }^{1}$ \\ ${ }^{1}$ Senior student- Higher Education Institute Iqbal Lahuri-Mashhad - Civil Engineering
}

\begin{abstract}
Structures and concrete reservoirs are considered as urban strategic installations that should have appropriate robustness in order to achieve passive defense. For example, concrete reservoirs playing an important role in the storage of drinking water and other vital fluids in country are considered among the highly important structures with respect to the kind of their application. This study was conducted using overview method to find a solution for retrofitting of concrete structures against earthquake and explosive loads. Introducing a variety of concrete reservoirs methods, it aims to examine its retrofitting methods. It also examines the effect of factors such as type of architecture and using shear wall on reducing the degradation of a concrete structure against earthquake and military attacks. The results showed that by increasing the length of the shear walls and when roofs are flat in concrete structures, we reduces the explosion degradation through surface air pressure and earth shock effect imposed on structure.
\end{abstract}

Secondly, using a variety of methods of retrofitting methods, we can ensure the strength of urban concrete structures during military and natural crisis.

Keywords: concrete structures and reservoirs, retrofitting-non-non-operating- passive defense

\section{Introduction}

Nowadays, due to development in science and industry, the results of wars are not determined in battlefield, but result of various attacks can be changed using preventive measures such as passive defense. Therefore, non-violent action leading to reduction in vulnerability of human resources, buildings, facilities, equipment, documents and vital arteries against hostilities and destructive actions of attackers is called passive defense. concrete structures is one of the most widely used type of structures that play a key role in the realization of defensive defense, since most of urban structures, reservoirs to keep liquids and bridges are among the concrete 
structures. As a result, the retrofitting of these kinds of structures should be investigated so that they are considered as our weakness in critical conditions they are used as strengths.

\section{Methodology}

This study was conducted using overview method.

\section{Findings}

Some general points on explosion and earthquake:

Explosion in a reaction in which materials are burnt at a rate faster than sound rate.

Based on the natural properties, it is divided into physical, chemical and nuclear modes and based on location it is divided to out of structure and within structure.

Generally, explosive load is applied on structures in three ways, including: Surface explosion air pressure load and earth shock wave load and simultaneous load of air pressure and earth shock effect.

\section{Controlling the structures}

As result of an explosion, large amount of energy is imposed on a concrete structure or drinking water reservoirs. Therefore, this structure must have the ability to absorb this energy so that explosion or an earthquake does not cause its destruction. Some of the methods to control structure include active control, semi-active control, inactive control, and double control. In the regulations, it has been specified that structures under earthquake with scalemedium Richter should not have considerable destruction and it is not destroyed as result of strong and high-Richter earthquakes, especially, its internal materials should be used effectively after the earthquake.

Retrofitting concrete structures: (1- specialized committee, subject 21)

In general, regulations of retrofitting and earthquake after earthquakes with high damage and loss of life are changing. In the past several years, the design of structures and earthquake engineering have been developed remarkably, since many concrete structures due to mistakes in the calculations, implementation, structure land used change, and lack of regulation against explosive impacts caused by war do not meet the new standards of regulations. As result, new methods of retrofitting were taken into account, including:

1 - The use of convergent or divergent Steel bracing

2 - The use of shear walls 
3 - Seismic cables

4 - Use of the moment frame

5 - Separating the base

6 - Use pre-tensioned and post-tensioned cables

In this article, we consider some of these methods.

Shear walls: (2- Office of National Building Regulations 2009)

In structural engineering, shear wall is a wall made of inhibitory components and its task is neutralizing the effect of the lateral loads entered on structures. Shear wall is designed to confront with common lateral loads such as earthquake and wind load. The lateral load is applied in one plate and in the vertical dimension of wall. These types of loads are transferred usually by members of the diaphragm or collector or drag into wall.

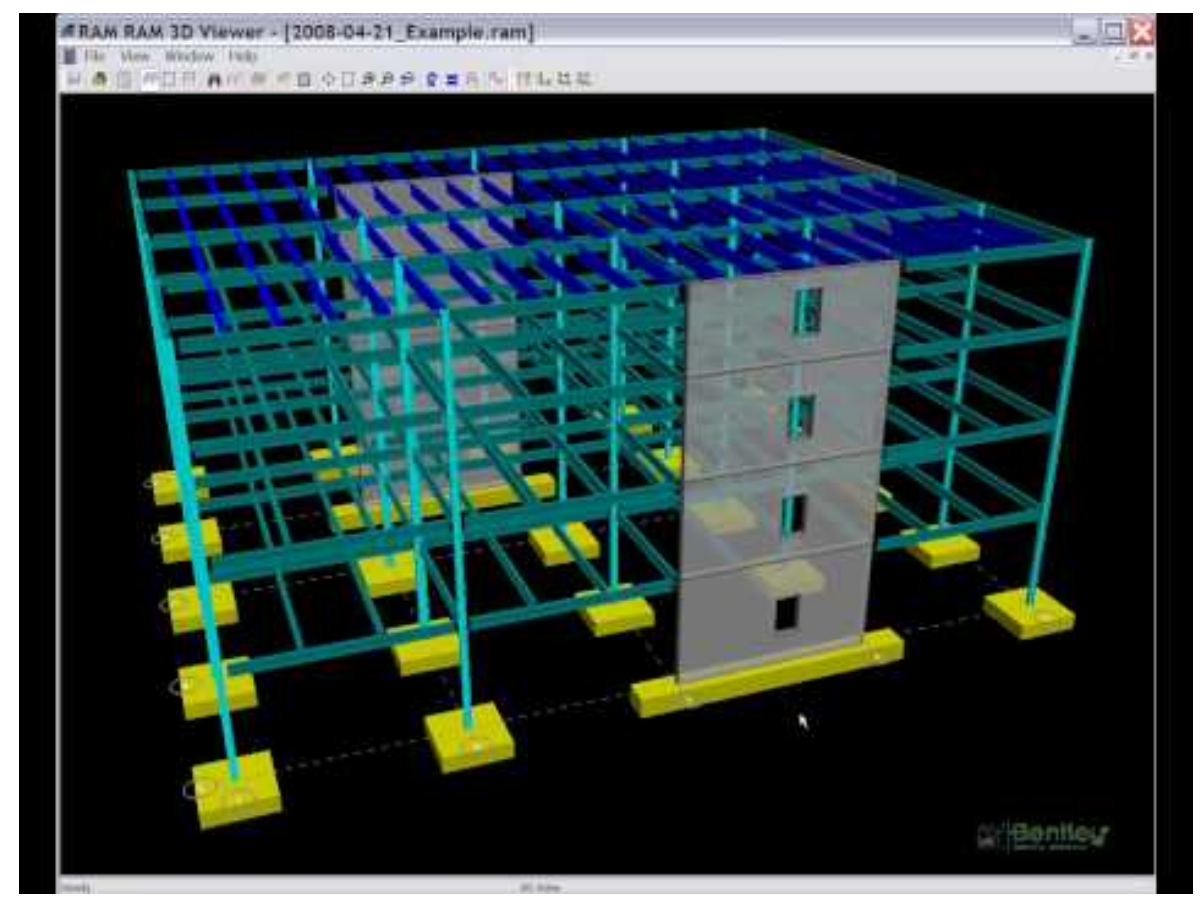

Fig. 1: Shear wall

In recent years, many experiments have been conducted to examine to retrofit shear wall structures. One of these experiments will be explained later (Ramjouyee 2013). Explosion was applied on three concrete structures with concrete shear walls with different lengths and $470470 \mathrm{~kg}$ TNT was placed at $5 \mathrm{~m}$ distance from structures so that distance and amount of explosive materials were equal for three structures. The results were compared with each other. Then, the mentioned structures were modelled. 
Each of the structures were analyzed dynamically 3 times separately under the surface explosion air pressure, earth shock wave load and simultaneous effect of air pressure and earth shock caused by surface explosion.

In the first concrete structure, when the structure of earth shock and explosion air pressure are entered, the final degradation rate is 3.96 of whole structure, and when structure is under explosion air effect, it is 2.5 of whole structure.

In the second structure that its wall shear is $1 \mathrm{~m}$ higher than the first structure, when the combined effect of air pressure and earth shock are entered to structure, degradation rate 1.49 percent of whole structure and if it is only under explosion air, it is $1.22 \%$ of whole structure. Accordingly, in the second structure that its wall shear is $1 \mathrm{~m}$ higher than the first structure, when the combined effect of air pressure and earth shock are entered to structure, degradation rate is 0.3 percent of whole structure and if it is only under explosion air, it is $0.25 \%$ of whole structure. In all three structures, the effect of earth shock alone is zero.

Pretensioned and seismic cables:

In 2003, Taylor and Wright examined pre-tensioned loop method (6-TAYLOR R.G. 2003) in cylindrical concrete reservoirs. They finally introduced three solutions for retrofitting the reservoirs. Firstly, they conducted experiments on cylindrical concrete reservoirs in the New Zealand and examined two types of connections in the section of foundation to wall connection. Then, they examined a pool using pre-tensioned concrete retrofitting. Then, they examined seismic retrofitting of roof and top of the prefabricated reservoir and studied them using seismic cables placed around the reservoir.

\section{Pre-tensioning}

In 2011, Dr. Karbaschi examined the pre-tensioning method. Using seismic pre-tensioned cables for pre-fabricated reservoirs, he achieved some advantages of this method as follows:

A- it is a quick method with the specified performance.

B- there is no need to remove structure in the retrofitting process.

C- it is very cheap method

Pre-tensioned method in bridges also plays a significant role in reducing the effects of explosive loads and forces exerted by earthquake. Obtained results from recent experiments have shown that shape, location, and number of cables in cross-section of the bridge deck are important parameters in designing a pre-tensioned cable system. 
In these experiments, it was shown that increasing the number of cables the degradation rate is reduced by $45 \%$. In addition, by deformation of pre-tensioned cables from direct to sagittal form, the degradation rate is reduced by $17 \%$.

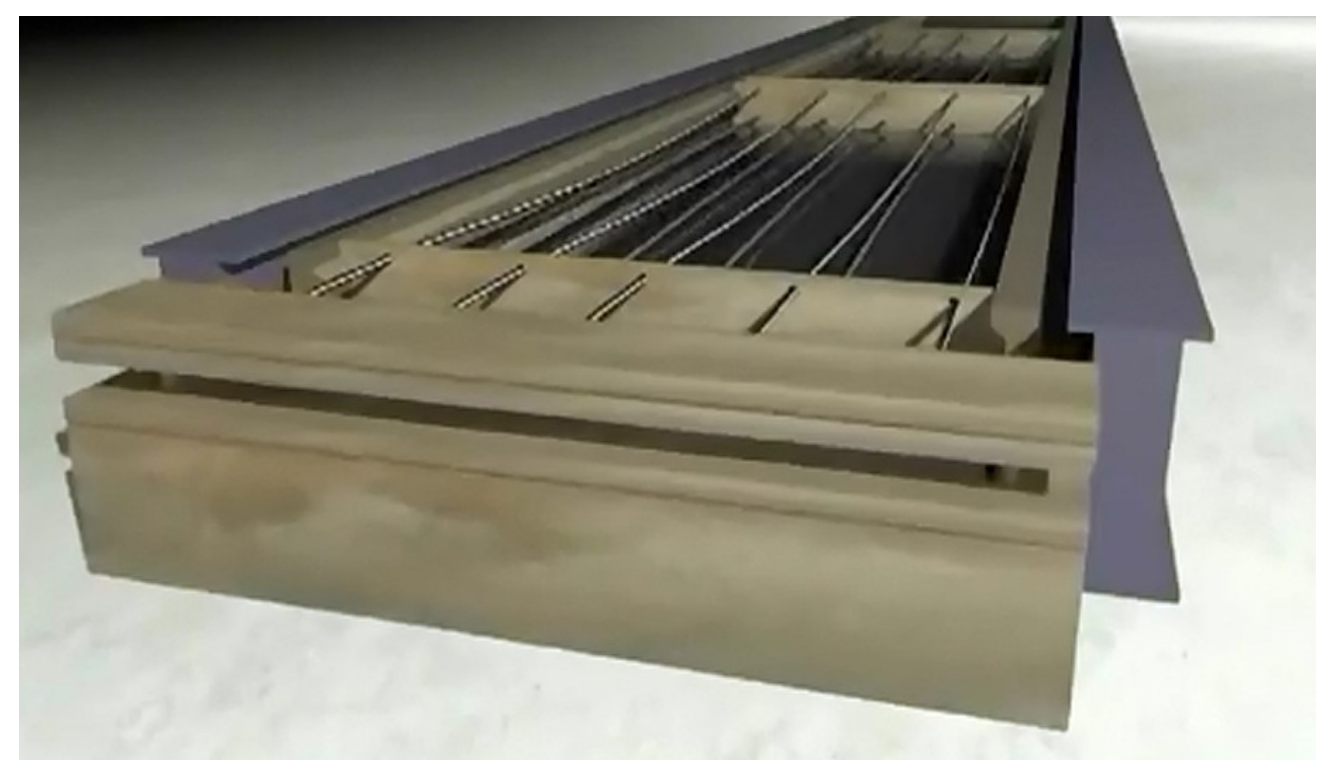

Fig. 2: Construction of pre-tensioned concrete

Architecture of building and its role in passive defense:

Retrofitting of buildings is not limited to make them strong and using new materials, but architecture of building plays an important role against explosive loads and earthquake. One of the effects of architecture can be examined in various types of roofs. Different types of roofs include: domical, pyramidal, conical, and flat. In the conducted studies, it has been specified that using flat surfaces contributes to reduced loses by explosive loads.

\section{Conclusion}

1. Based on conducted experiments and studies, it can be concluded that firstly different types of concrete structures retrofitting methods can be applied also in reservoirs. Secondly, in these experiments, it was found that when the length of shear wall is high, structure will have better performance against explosive loads and earthquake. We also examined the pre-tensioning in structures. Based obtained results, it was found that I has very high advantages in terms of economy and structure. In addition, it was found that by changing in the number of mode of cables in the bridges designed by pre-tensioned method, degradation rate caused by explosion might be reduced. 
2. In these studies, it was found that type of building architecture has not been considered so much by experts in line with realization of passive defense, but we studied this issue in the current paper.

\section{References}

1. Specialized Committee of twenty- fist subject 2009. Sixth edition, passive defense.

2. Office of national regulations of building, 2009, ninth subject of national regulations of building and development of Iran.

3. Razmjouyee, M, Ayazi, A, the impact of the shear wall on reduction of degradation rate caused combined effect of earth shock surface explosion air pressure on concrete structures, 2013.

4. Keivanlou. S, 2011. Retrofitting of concrete structures, Islamic Azad University of Torbate-Heidarie.

5. Mahdavi Sefat, E, Vatani, M, numerical investigation of behavior of prefabricated pretensioned reinforced concrete bridges under explosive load, 2014.

6. R.G. Taylor, P.D. Wright, Innovative seismic retrofit of concrete water supply tanks, 2003 pacific conference on erthquake engineering, 2003.

7. M.E.Karbaschi, R.Goudarzizadeh and N.Hedayat, Efficiency of Post-Tensioning Method for Seismic Retrofitting of Pre-Cast Cylindrical Concrete Reservoirs, World Academy of Science, Engineer Technology 73, 2011 